\title{
Chemical and Biological Studies of Cannabis sativa Roots
}

\author{
Mostafa A. Elhendawy ${ }^{a, b}$ Amira S. Wanas ${ }^{a, c}$ Mohamed M. Radwan ${ }^{a}$ \\ Nabil A. Azzaz ${ }^{\text {b ElShahat S. Toson }}{ }^{d}$ Mahmoud A. ElSohlya, e \\ ${ }^{a}$ National Center for Natural Products Research, School of Pharmacy, University of Mississippi, University, MS, \\ USA; 'bepartment of Chemistry, Faculty of Agriculture, Damietta University, Damietta, Egypt; ' Department of \\ Pharmacognosy, Faculty of Pharmacy, Minia University, Minia, Egypt; ${ }^{d}$ Department of Chemistry, Faculty of Science, \\ Damietta University, Damietta, Egypt; ${ }^{e}$ Department of Pharmaceutics and Drug Delivery, School of Pharmacy, \\ University of Mississippi, University, MS, USA
}

\section{Keywords}

Cannabis sativa $\cdot$ Secondary metabolites $\cdot$ High-performance liquid chromatography - Quantitative analysis .

Cannabis roots

\begin{abstract}
The chemical study of Cannabis sativa roots led to the isolation and identification of 10 compounds. Their chemical structures were unambiguously established on the basis of 1D and 2D NMR spectroscopy and mass spectrometry as friedelan-3-one (1), epifriedelanol (2), $\beta$-sitosterol (3), ergost-5en-3-ol (4), methyl hexadecanoate (5), pentadecanoic acid (6), 10E-hexadecenoic acid (7), 4-hydroxy-3-methoxybenzaldehyde (8), $\beta$-sitosterol- $\beta$-D-glucoside (9) and $p$-coumaroyltyramine (10). Compounds 5-9 were reported for the first time from $C$. sativa roots. All the isolated compounds were tested for their antimicrobial activity. Compound 4 showed modest activity against Cryptococcus neoformans with an $I C_{50}$ value of $13.7 \mu \mathrm{g} / \mathrm{mL}$, while compound 10 displayed potent activity against Escherichia coli with an $\mathrm{IC}_{50}$ value of 0.8 $\mu \mathrm{g} / \mathrm{mL}$. A high-performance liquid chromatography method was developed and validated for the detection and quantification of $p$-coumaroyltyramine (10) in the extracts of different varieties of $C$. sativa roots.

(c) 2018 The Author(s)

Published by S. Karger AG, Basel
\end{abstract}

\section{KARGER}

E-Mail karger@karger.com www.karger.com/mca

\section{(C) 2018 The Author(s) \\ Published by S. Karger AG, Basel \\ Karge \\ Open access}

This article is licensed under the Creative Commons AttributionNonCommercial-NoDerivatives 4.0 International License (CC BYNC-ND) (http://www.karger.com/Services/OpenAccessLicense). Usage and distribution for commercial purposes as well as any distribution of modified material requires written permission.

\section{Introduction}

Cannabis sativa L. is one of the most widely used plants for both recreational and medicinal purposes. To date, a total of 567 natural constituents covering several chemical classes have been identified from $C$. sativa $[1,2]$. The most important classes are the cannabinoids, terpenoids, nitrogenous compounds, noncannabinoid phenols, flavonoids, and steroids [3]. The principal use of cannabis in medicine is for easing pain and in ameliorating nervous system disorders. It is reported to be useful in the treatment of gout, neuralgia, rheumatism, insanity, and insomnia among others, with actions almost entirely on the higher nerve centers [4].

The first reference to cannabis consumption dates as far back as 2,700 BC in China, with Shennong pên Ts'ao ching, one of the oldest Chinese medicine books, mentioning the use of cannabis roots as a remedy to sooth pain. Throughout history, cannabis roots were documented in ancient Greek medicine, and a medical article in how Indians boiled them together with other leaves to make poultices for the treatment of inflamed skin surfaces and skin rash $[3,5]$. There are numerous reports on the traditional use of cannabis root for the treatment of fever, inflammation, gout, arthritis, and joint pain, as well 
as skin burns and hard tumors [3]. Also, they were used to treat postpartum hemorrhage, difficult child labor, sexually transmitted disease, and gastrointestinal activity and infection [6]. Despite a long history of therapeutic use, the roots of cannabis plants have been ignored in modern medical research and practice. Cannabis roots have been reported to have many different compounds, including triterpenoids, monoterpenes, alkaloids, sterols, amides, and choline [3].

On continuation of our search for bioactive compounds from C. sativa $[7,8]$, this article describes the isolation and structural elucidation as well as the antimicrobial activity of 10 compounds from $C$. sativa roots. A high-performance liquid chromatography (HPLC) method was also developed and validated for the quantification of $p$-coumaroyltyramine (10) in extracts of different varieties of $C$. sativa roots which could be used as a possible marker compound to distinguish between roots of different varieties of C. sativa.

\section{Materials and Methods}

\section{General Experimental Procedures}

$1 \mathrm{D}$ and 2D NMR spectra were recorded using the residual solvent signal as an internal standard on Bruker BioSpin Gm bH 400 and 500 NMR spectrometers (Bruker, Rheinstetten, Germany). Thin-layer chromatography (TLC) was carried out on aluminumpacked plates precoated with silica gel $\mathrm{F}_{254}$ (Silicycle, Quebec, QC, Canada). Visualization was accomplished by spraying with a vanillin sulfuric acid spray reagent followed by heating.

\section{Plant Material}

C. sativa plants were grown at the University of Mississippi, USA and identified by Dr. Suman Chandra, senior scientist, NCNPR, School of Pharmacy, University of Mississippi. The fresh roots were washed with tap water followed by distilled water and dried under shade. The dried roots were powdered using a coffee grinder.

\section{Extraction and Isolation}

The dried ground roots of a high cannabidiol (CBD) variety of cannabis $(2.0 \mathrm{~kg})$ were sequentially extracted with hexanes $(2 \times$ $16 \mathrm{~L})$, dichloromethane $\left(\mathrm{CH}_{2} \mathrm{Cl}_{2}\right)(20 \mathrm{~L})$, ethyl acetate (EtOAc) $(20$ $\mathrm{L})$, and methanol $(\mathrm{MeOH})(20 \mathrm{~L})$ at room temperature. The extracts were evaporated under reduced pressure at $40{ }^{\circ} \mathrm{C}$ to afford hexanes (3.8 g), $\mathrm{CH}_{2} \mathrm{Cl}_{2}(3.5 \mathrm{~g})$, EtOAc (1.4 g) and $\mathrm{MeOH}(0.5 \mathrm{~g})$ extracts. The hexanes extract $(3.8 \mathrm{~g})$ was subjected to silica gel column chromatography $(75 \times 2.5 \mathrm{~cm}$ i.d. $)$, eluted with EtOAc/nhexane $(0: 100,10: 90,20: 80,30: 70,40: 60,50: 50,75: 25,100: 0 \mathrm{v} / \mathrm{v}$ [1.0 L of each mixture]), yielding 10 fractions $\left(\mathrm{H}_{1}-\mathrm{H}_{10}\right)$. Fraction $\mathrm{H}_{1}(197.8 \mathrm{mg}$ ) was applied to a C18 solid-phase extraction column eluted with $\mathrm{MeOH} / \mathrm{H}_{2} \mathrm{O}$ (75:25), to afford compound 1 (127 mg) and compound $2(46.3 \mathrm{mg})$. Fraction $\mathrm{H}_{5}(717.9 \mathrm{mg})$ was fractionated over a silica gel column $(45 \times 2 \mathrm{~cm}, 50 \mathrm{~g})$ and eluted with EtOAc/n-hexane (0:100-20:80, 5\% stepwise) to afford compound

Chemical and Biological Studies of

Cannabis sativa Roots
3 and 4 subfractions (A-D). Subfraction A $(54.4 \mathrm{mg})$ was purified on a $5.0 \mathrm{~g}$ solid-phase extraction amino column eluted with $\mathrm{CH}_{2} \mathrm{Cl}_{2}$ $(50 \mathrm{~mL}), 5 \%$ isopropanol $/ \mathrm{CH}_{2} \mathrm{Cl}_{2}(50 \mathrm{~mL}), 2 \%$ acetic acid/diethyl ether $(50 \mathrm{~mL})$ and $\mathrm{MeOH}(50 \mathrm{~mL})$ to yield compound $4(21 \mathrm{mg})$. The $\mathrm{CH}_{2} \mathrm{Cl}_{2}$ and EtOAc extracts were mixed together $(4.9 \mathrm{~g})$ based on TLC analysis; subjected to silica gel column chromatography $(100 \times 3.5 \mathrm{~cm}, 150 \mathrm{~g})$, using EtOAc/ $\mathrm{CH}_{2} \mathrm{Cl}_{2}$ as eluant $(0: 100-100$ : $0,5 \%$ stepwise), to yield 10 fractions $\left(\mathrm{DE}_{1}-\mathrm{DE}_{10}\right)$. Fraction $\mathrm{DE}_{1}$ $(104.2 \mathrm{mg})$ was chromatographed over a silica gel column $(50 \times 1$ $\mathrm{cm}, 19 \mathrm{~g})$ and eluted with chloroform $\left(\mathrm{CHCl}_{3}\right) / \mathrm{n}$-hexane mixture $(0: 100,30: 70,50: 50,70: 30,100: 0$ [80 $\mathrm{mL}$ of each mixture]), to yield compound $5(20 \mathrm{mg})$. Fraction $\mathrm{DE}_{2}(237.9 \mathrm{mg})$ was chromatographed on a silica gel column using $100 \%$ dichloromethane as a mobile phase to afford compounds $6(17.7 \mathrm{mg}), 7(63.7 \mathrm{mg})$ and 8 (15.2 mg). Fraction $\mathrm{DE}_{9}(540.5 \mathrm{mg})$ was applied to a $\mathrm{C}_{18} \mathrm{RP}$ silica column $(30 \times 2 \mathrm{~cm}, 50 \mathrm{~g})$ eluting with $\mathrm{MeOH} / \mathrm{H}_{2} \mathrm{O}(75: 25,80$ : $20,90: 10,100: 0)$, to afford compounds $9(25 \mathrm{mg})$ and $10(8.2 \mathrm{mg})$.

\section{In vitro Antimicrobial Assay}

All organisms used for the biological evaluation were obtained from the American Type Culture Collection (Manassas, VA, USA). These include the fungi Candida albicans ATCC 90028, Cryptococcus neoformans ATCC 90113, and Aspergillus fumigatus ATCC 90906 and the bacteria methicillin-resistant Staphylococcus aureus ATCC 43300 (MRS), Escherichia coli ATCC 35218, Pseudomonas aeruginosa ATCC 27853, Klebsiella pneumoniae ATCC 25955 , and vancomycin-resistant enterococcus. Susceptibility testing was performed using a modified version of the CLSI (formerly NCCLS) methods as previously described $[9,10]$.

\section{HPLC Analysis of p-Coumaroyltyramine (10)}

Reagents and Materials

Acetonitrile $\left(\mathrm{CH}_{3} \mathrm{CN}\right), \mathrm{MeOH}$, tetrahydrofuran, and $\mathrm{H}_{2} \mathrm{O}$ are of HPLC grade (Fisher Scientific, Fairlawn, NJ, USA). Compound 10 was isolated from the roots of C. sativa. The chemical structure of compound 10 was identified by ${ }^{1} \mathrm{H}$ NMR, ${ }^{13} \mathrm{C} \mathrm{NMR}$, heteronuclear multiple-quantum correlation, heteronuclear multiple-bond correlation, and electrospray ionization mass spectrometry. The ${ }^{1} \mathrm{H}$ and ${ }^{13} \mathrm{C}$ NMR data of compound 10 are shown in Table 1 and Figure 1 . The purity of compound 10 was determined on the basis of UV, NMR, MS and HPLC to be $>98 \%$.

Apparatus and Chromatographic Conditions

A Waters 9526 HPLC system equipped with a quaternary solvent delivery system, an autosampler and a DAD detector were used. Separation was achieved on a Phenomenex luna C18 column $(250 \times 4.6 . \mathrm{mm}$ i.d., $5 \mu \mathrm{m}$ particle size $)$. The mobile phase consisted of (a) $\mathrm{CH}_{3} \mathrm{CN}: \mathrm{MeOH}(1: 1)$ and (b) $\mathrm{H}_{2} \mathrm{O}$. The gradient elution (\% a in b) was as follows: $0-8 \mathrm{~min}$, linear gradient from 30 to $45 \%$; $8-10 \mathrm{~min}$, linear gradient to $50 \%$; $10-15 \mathrm{~min}$, linear gradient to $60 \%$, which was held for $5 \mathrm{~min}$ then returned to $30 \%$. Each run was followed by equilibration time of $5 \mathrm{~min}$. The flow rate was $1.0 \mathrm{~mL} /$ $\mathrm{min}$ and the total run time was $20 \mathrm{~min}$. The column temperature was set at $30^{\circ} \mathrm{C}$. DAD spectra were monitored from 210 to $480 \mathrm{~nm}$ and the detection wavelength was set to $\lambda_{\max } 290 \mathrm{~nm}$. The injection volume was $10 \mu \mathrm{L}$.

Preparation of Standard Solutions and Calibration Curve

A $1.0 \mathrm{mg} / \mathrm{mL}$ stock solution of compound 10 in $\mathrm{MeOH}$ was prepared and diluted to an appropriate concentration range to es- 
Table 1. ${ }^{1} \mathrm{H}(400 \mathrm{MHz})$ and ${ }^{13} \mathrm{C} \mathrm{NMR}(100 \mathrm{MHz})$ spectroscopic data of $p$-coumaroyltyramine (compound 10) (DMSO) ${ }^{\mathrm{a}}$

\begin{tabular}{lll}
\hline Carbon & \multicolumn{2}{l}{ Compound 10} \\
\cline { 2 - 3 } & $\delta_{\mathrm{C}}$ & $\delta_{\mathrm{H}}$, mult. $(\mathrm{Jin} \mathrm{Hz})$ \\
\hline 1 & 159.1 & \\
2,6 & 115.4 & $6.71, \mathrm{~d}(8.4)$ \\
3,5 & 129.5 & $7.02, \mathrm{~d}(8.4)$ \\
4 & 126.2 & \\
7 & 139.1 & $7.38, \mathrm{~d}(16.0)$ \\
8 & 118.9 & $6.45, \mathrm{~d}(16.0)$ \\
9 & 165.8 & \\
10 & 34.7 & $2.69, \mathrm{~d}(7.4)$ \\
11 & 41.0 & $3.38, \mathrm{~m}$ \\
12 & 129.8 & \\
13,17 & 129.7 & $7.39, \mathrm{~d}(8.4)$ \\
14,16 & 116.0 & $6.81, \mathrm{~d}(8.4)$ \\
15 & 155.9 & \\
$\mathrm{NH}$ & & $8.06, \mathrm{t}(5.7)$ \\
\hline
\end{tabular}

a Assignment conformed by distortionless enhancement by polarization transfer 135, heteronuclear multiple-quantum correlation, COSY and heteronuclear multiple-bond correlation NMR experiment.

tablish the calibration curve. The calibration curve was constructed at $1,5,10,25,50,75$ and $100 \mu \mathrm{g} / \mathrm{mL}$ each in triplicate.

\section{Preparation of Sample Solutions}

Three different varieties of $C$. sativa roots (high CBD, intermediate, high tetrahydrocannabinol [THC] variety) were separately ground. Each sample (1.0 g) was accurately weighed and extracted with $10 \mathrm{~mL}$ tetrahydrofuran by sonication for $30 \mathrm{~min}$ and $5.0 \mathrm{~mL}$ of the extract was dried with $\mathrm{N}_{2}$. The final volume was adjusted to $1.0 \mathrm{~mL}$ with $\mathrm{MeOH}$, filtered through a $0.45-\mu \mathrm{m}$ filter and the filtrate injected into the HPLC system.

Method Validation

The method was validated for linearity, precision (interday, intraday and intermediate precision), accuracy, stability, specificity, and selectivity following the International Conference on Harmonization (ICH) guideline [11].

\section{Results and Discussion}

\section{Identification of the Isolated Compounds}

Compounds 1-10 (Fig. 2) were identified by comparing their spectroscopic characteristics with those previously reported in the literature as friedelan-3-one (1) [12], epifriedelanol (2) [12], $\beta$-sitosterol (3) [13], ergost5-en-3-ol (4) [14], methyl hexadecanoate (5) [15], pentadecanoic acid (6) [16], 10E-hexadecenoic acid (7) [16], 4-hydroxy-3-methoxybenzaldehyde (8) [17], and $\beta$-sitosterol- $\beta$-D-glucoside (9) [18]. Compound 10 was isolated as white amorphous powder. Its positive reaction using the ferric chloride test showed the phenolic nature of this compound. The molecular formula of 10 was deduced as $\mathrm{C}_{17} \mathrm{H}_{17} \mathrm{O}_{3} \mathrm{~N}$ from LRESIMS analysis which showed a protonated molecular ion $[\mathrm{M}+\mathrm{H}]^{+}$at $\mathrm{m} / z 284$ in the positive ionized mode. The ${ }^{13} \mathrm{C}$ NMR spectrum of 10 (Table 1; Fig. 1) showed 13 carbon signals which were sorted by distortionless enhancement by polarization transfer and heteronuclear multiple-quantum correlation techniques as two methylenes $\left(\delta_{\mathrm{C}} 34.7 / \delta_{\mathrm{H}} 2.69 ; \delta_{\mathrm{C}}\right.$ $\left.41.0 / \delta_{\mathrm{H}} 3.38\right)$ and six methynes $\left(\delta_{\mathrm{C}} 116 / \delta_{\mathrm{H}} 6.81 ; \delta_{\mathrm{C}} 115.4 /\right.$ $\delta_{\mathrm{H}} 6.71 ; \delta_{\mathrm{C}} 118.9 / \delta_{\mathrm{H}} 6.45 / ; \delta_{\mathrm{C}} 129.5 / \delta_{\mathrm{H}} 7.02 ; \delta_{\mathrm{C}} 129.7 / \delta_{\mathrm{H}}$ $\left.7.39 ; \delta_{\mathrm{C}} 139 / \delta_{\mathrm{H}} 7.38\right)$. The five remaining carbon signals were attributed to quaternary carbons among which one amide carbonyl at $\delta_{\mathrm{C}} 165.8$ and two oxygenated aromatic carbon at $\delta_{\mathrm{C}} 159.1$ and $\delta_{\mathrm{C}} 155.9$. The ${ }^{1} \mathrm{H}$ NMR spectrum of 10 exhibited 8 proton signals which were analyzed using correlation spectroscopy spectrum that showed two AA'BB' system attributed to two para substituted aromatic moieties, respectively, at $\delta_{\mathrm{H}} 7.02$ and $\delta_{\mathrm{H}} 6.71(\mathrm{~J}=8.4$ $\mathrm{Hz}) ; \delta_{\mathrm{H}} 7.39$ and $\delta_{\mathrm{H}} 6.81(J=8.4 \mathrm{~Hz})$; one pair of doublet of trans substituted ethylene moiety protons at $\delta_{\mathrm{H}} 7.38$ and $\delta_{\mathrm{H}} 6.45(\mathrm{~J}=16.0 \mathrm{~Hz})$ and one multiple and one triplet of two protons each attributed to 1,2-disubstituted ethane moiety at $\delta_{\mathrm{H}} 3.38$ and $\delta_{\mathrm{H}} 2.69(\mathrm{~J}=7.4 \mathrm{~Hz})$. The heteronuclear multiple-bond correlation between the ethylene proton $\left(\delta_{\mathrm{H}} 7.38, \mathrm{H}-7\right)$ with both the amide carbonyl $\left(\delta_{\mathrm{C}}\right.$ $165.8, \mathrm{C}-9)$ and the aromatic carbon $\left(\delta_{\mathrm{C}} 129.5, \mathrm{C}-3\right.$ and C5) confirms the presence of the trans-coumaroyl moiety, while the heteronuclear multiple-bond correlation between the ethyl proton $\left(\delta_{\mathrm{H}} 2.69, \mathrm{H}-10\right)$ with both the amide carbonyl $\left(\delta_{\mathrm{C}} 165.8, \mathrm{C}-9\right)$ and the quaternary aromatic carbon at $\delta_{\mathrm{C}} 129.8(\mathrm{C}-12)$ supports the presence of the tyramine moiety. Based on the above data and comparing with literature [19], the chemical structure of compound 10 was elucidated to be N-p-trans-coumaroyltyramine.

\section{Antimicrobial Activity}

The antimicrobial activities of all isolated compounds were determined against methicillin-resistant $S$. aureus (MRSa), E. coli, P. aeruginosa, and Mycobacterium intracellulare, as well as against pathogenic fungi including C. albicans, A. fumigatus, and C. neoformans. Compounds 4 and 10 showed antimicrobial activity. Compound 4 was active against $C$. neoformans with an $\mathrm{IC}_{50}$ value of $13.7 \mu \mathrm{g} /$ $\mathrm{mL}$, while compound 10 was active against $E$. coli with an $\mathrm{IC}_{50}$ value of $0.8 \mu \mathrm{g} / \mathrm{mL}$ (Table 2 ). 


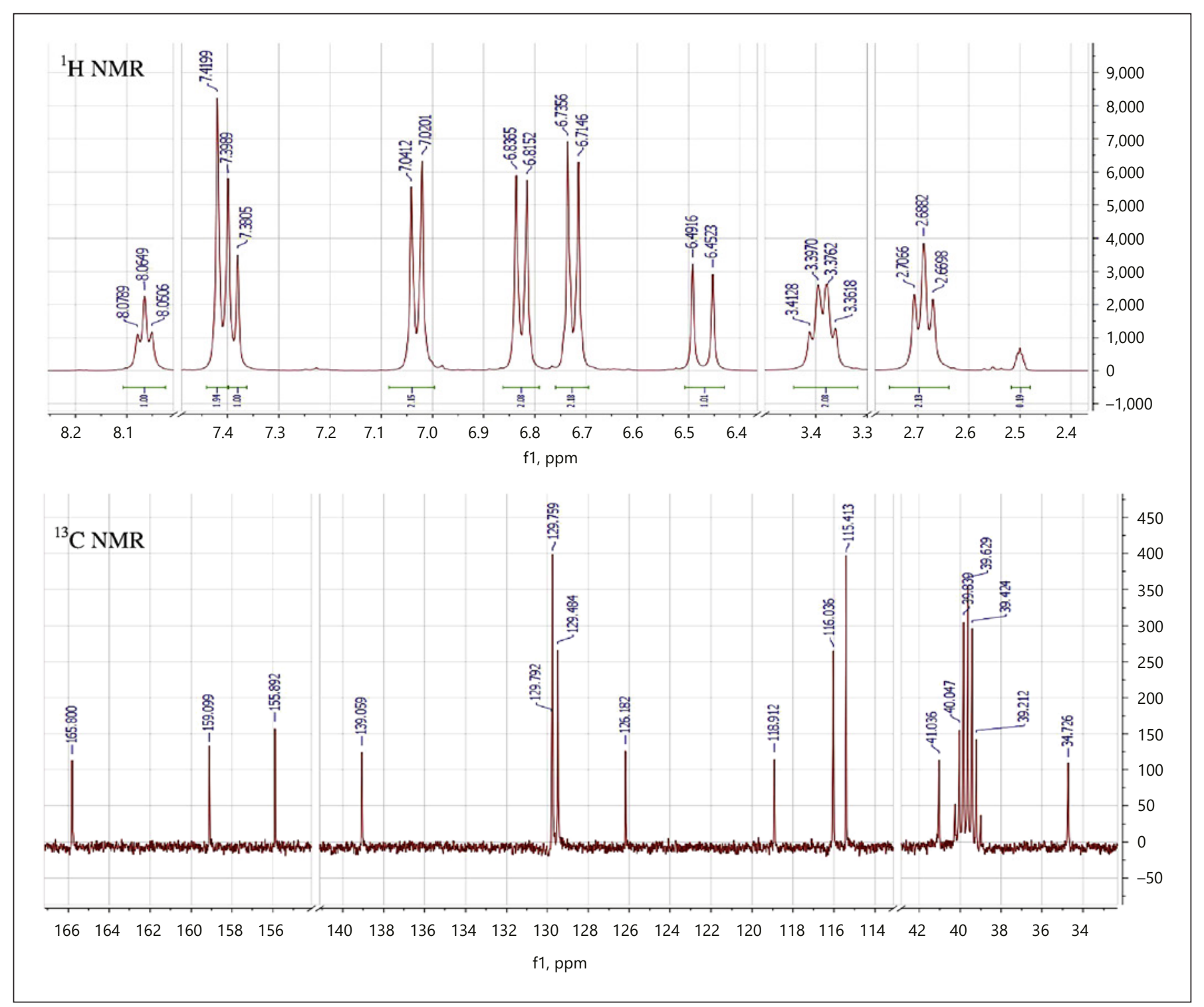

Fig. 1. ${ }^{1} \mathrm{H}(400 \mathrm{MHz})$ and ${ }^{13} \mathrm{C}$ NMR $(100 \mathrm{MHz})$ spectra of compound 10.

\section{HPLC Analysis}

Plant constituents vary considerably based on several factors such as temperature, light, drying, packing, and storage, which may impair not only the quality of phytotherapeutic agents but also their therapeutic value [20]. Thus, standardization of raw materials and herbal preparations needs to be permanently carried out in term of quality specification, stability profiles and chemical analysis of analytes of interest using sensitive validated analytical methods [21]. HPLC is a unique, versatile, universal and well-recognized tool for qualitative and quantita-
Table 2. In vitro antimicrobial activities of compound 4 and 10 $\left(\mathrm{IC}_{50}\right.$ in $\left.\mu \mathrm{g} / \mathrm{mL}\right)$

\begin{tabular}{lll}
\hline Compound & $\begin{array}{l}\text { Antifungal } \\
\text { C. neoformans }\end{array}$ & $\begin{array}{l}\text { Antibacterial } \\
\text { E. coli }\end{array}$ \\
\hline 4 & 13.67 & na \\
10 & na & 0.8 \\
Ciprofloxacin & na & 0.01 \\
Amphotericin B & 1.29 & na \\
\hline
\end{tabular}

$\mathrm{IC}_{50}$, the concentration that causes $50 \%$ inhibition of growth; na, not active. 
Fig. 2. Structure of compounds $1-10$ isolated from $C$. sativa roots.

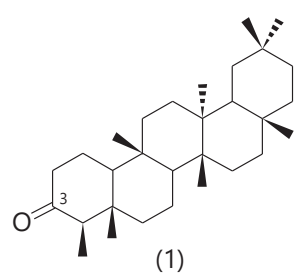

(1)

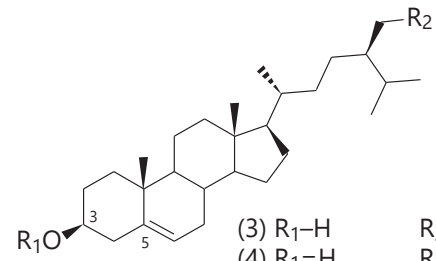

(4) $\mathrm{R}_{1}=\mathrm{H} \quad \mathrm{R}_{2}=\mathrm{H}$

(9) $\mathrm{R}_{1}=$ Glucose $\mathrm{R}_{2}-\mathrm{CH}_{3}$

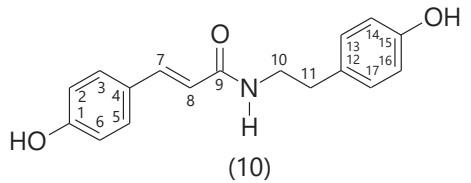

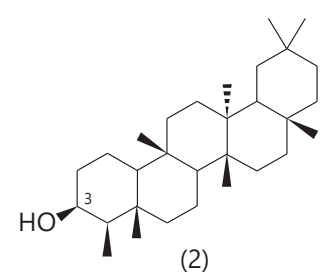

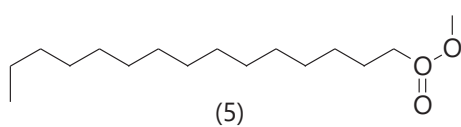

(5)

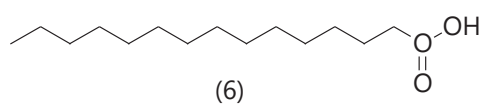

(6)

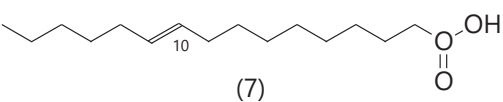

(7)

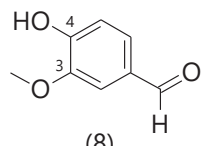

(8) tive evaluation of herbal products against their respective bioactive molecules in terms of quality and batch-tobatch reproducibility [22]. Thus, in this study contribution, we have developed a simple, economic and rapid chromatographic method using RP-HPLC for the estimation of $p$-coumaroyltyramine (10) in different varieties of $C$. sativa roots.

\section{Method Validation}

Compound 10 was detected and quantified by HPLC, usingagradientmobile phase consisting of $\mathrm{CH}_{3} \mathrm{CN}: \mathrm{MeOH}$ (1:1) and $\mathrm{H}_{2} \mathrm{O}$. Compound 10 showed a sharp peak at 8.81 \pm 0.015 min under the optimized chromatographic conditions at $\lambda_{\max } 290 \mathrm{~nm}$. Representative chromatograms are depicted in Figure 3. The separation of the marker compound (10) in a short time enabled rapid analysis of the samples. The calibration curve showed good linearity relationship in the specified concentration range (1-100 $\mu \mathrm{g} / \mathrm{mL}$ ) with a correlation coefficient $\left(r^{2}\right)$ of 0.9996 (Fig. 3; Table 3). The limits of detection and quantification were found to be $0.025 \mu \mathrm{g} / \mathrm{mL}$ and $0.1 \mu \mathrm{g} / \mathrm{mL}$, respectively, thus suggesting a high sensitivity of the method which can be successfully exploited for quantifying even low sample concentrations of compound 10 (Table 3). The relative standard deviation for system suitability in terms of $R_{t}$

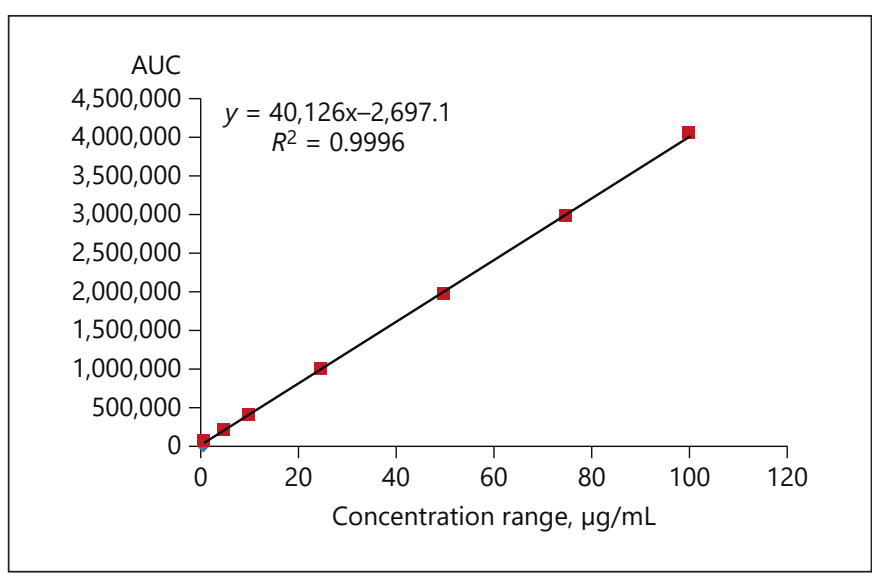

Fig. 3. Calibration curve of $p$-coumaroyltyramine (compound 10).

and area were found to be less than $6 \%$ indicating the stability of the chromatographic method. The percent relative standard deviation of inter- and intraday analysis of standard and extract were also found to be less than 7 with a high repeatability of both $\mathrm{R}_{\mathrm{t}}$ and response (Table 3 ). Mean recovery for the quality control samples of $p$-coumaroyltyramine (10) was found to be $>98 \%$ (Table 4). 
Table 3. Results of validation of $p$-coumaroyltyramine (compound 10) using HPLC in terms of linearity, sensitivity, and precision

\section{Parameters}

$\begin{array}{ll}\text { Linearity }(n=3) & \\ \text { Concentration range, } \mu \mathrm{g} / \mathrm{mL} & 0.25-100 \\ \text { Regression equation } & \mathrm{Y}=40126 \mathrm{X}-2697.1 \\ \text { Correlation coefficient }\left(r^{2}\right) & 0.9996\end{array}$

\begin{tabular}{ll}
\hline Sensitivity & \\
$\mathrm{LOD}, \mu \mathrm{g} / \mathrm{mL}$ & 0.25 \\
$\mathrm{LOQ}, \mu \mathrm{g} / \mathrm{mL}$ & 0.75
\end{tabular}

\begin{tabular}{|c|c|c|c|c|c|c|}
\hline \multicolumn{7}{|l|}{ Precision $(n=6)$} \\
\hline & \multicolumn{2}{|c|}{ Concentration, $\mu \mathrm{g} / \mathrm{mL}$} & \multicolumn{2}{|l|}{ Area } & \multicolumn{2}{|l|}{$\mathrm{R}_{\mathrm{t}}, \min$} \\
\hline & mean $\pm S D$ & $\%$ RSD & mean $\pm \mathrm{SD}$ & $\%$ RSD & mean $\pm \mathrm{SD}$ & $\%$ RSD \\
\hline \multicolumn{7}{|l|}{ Intraday } \\
\hline 1st day & $22.03 \pm 1.25$ & 5.69 & $439,467 \pm 25,147.32$ & 5.72 & $8.80 \pm 0.037$ & 0.427 \\
\hline 2nd day & $23.40 \pm 0.24$ & 1.07 & $464,383.66 \pm 5,000.918$ & 1.08 & $8.76 \pm 0.015$ & 0.176 \\
\hline 3rd day & $20.52 \pm 0.99$ & 4.87 & $409,044.66 \pm 20,060.68$ & 4.90 & $8.80 \pm 0.027$ & 0.32 \\
\hline Interday & $21.98 \pm 1.43$ & 6.55 & $437,631.78 \pm 10,476.54$ & 2.39 & $8.79 \pm 0.011$ & 0.13 \\
\hline
\end{tabular}

LOD, limit of detection; LOQ, limit of quantitation; RSD, relative standard deviation.

Table 4. Recovery of $p$-coumaroyltyramine (compound 10) from the sample

\begin{tabular}{llll}
\hline $\begin{array}{l}\text { Amount spiked, } \\
\mu \mathrm{g} / \mathrm{mL}\end{array}$ & $\begin{array}{l}\text { Amount recovered } \\
(\mathrm{mean} \pm \mathrm{SD}),\end{array}$ & \% Recovery & \% RSD \\
& $\mu \mathrm{g} / \mathrm{mL}$ & & \\
\hline 5 & $4.97 \pm 0.413$ & $99.56 \pm 0.082$ & 8.31 \\
25 & $24.55 \pm 0.852$ & $98.22 \pm 0.034$ & 3.47 \\
50 & $49.95 \pm 0.081$ & $99.92 \pm 0.002$ & 0.16 \\
\hline
\end{tabular}

Because of the almost quantitative recovery of compound 10 and the consistency of the analysis, the external standard method was adopted for quantification.

\section{Method Application}

The validated method was employed for the quantitation of $p$-coumaroyltyramine (10) from different varieties of $C$. sativa roots, namely high $\mathrm{CBD}$, intermediate and high THC varieties. The HPLC profiles of the cannabis extracts samples showed a sharp peak for compound 10 at $\mathrm{R}_{\mathrm{t}} 8.81( \pm 0.015)$ min comparable to the standard. Figure 4 demonstrates a clear baseline separation of compound 10 in the three varieties of cannabis from adjacent peaks. The content of compound 10 in the high CBD variety was $19.78 \pm 0.728 \mu \mathrm{g} / \mathrm{g}$, while in the intermediate and high THC varieties it was $8.00 \pm 0.348$ and $7.65 \pm 0.359 \mu \mathrm{g} / \mathrm{g}$,
Table 5. The content of $p$-coumaroyltyramine (compound 10) in C. sativa roots of three different varieties determined by HPLC

\begin{tabular}{lcc}
\hline Sample & \multicolumn{2}{c}{ Compound $10, \mu \mathrm{g} / \mathrm{g}$} \\
\cline { 2 - 3 } & mean $\pm \mathrm{SD}(n=6)$ & $\% \mathrm{RSD}$ \\
\hline High CBD variety & $19.78 \pm 0.728$ & 3.68 \\
Intermediate variety & $8.00 \pm 0.348$ & 4.35 \\
High THC variety & $7.65 \pm 0.359$ & 4.70 \\
\hline
\end{tabular}

respectively. The representative chromatograms and values are shown in Figure 4 and Table 5, respectively.

\section{Conclusion}

Ten compounds have been isolated and identified from a high CBD variety of cannabis roots, of which compounds 4 and 10 showed promising antimicrobial activities. A validated HPLC method for the quantitation of compound 10 in three varieties of C. sativa was developed. The method was fast, simple and accurate and could be used for routine analysis of this marker compound in cannabis roots. Whether this compound can be used as a marker to discriminate between $\mathrm{CBD}$ variety roots and the other two varieties need to be further investigated. 


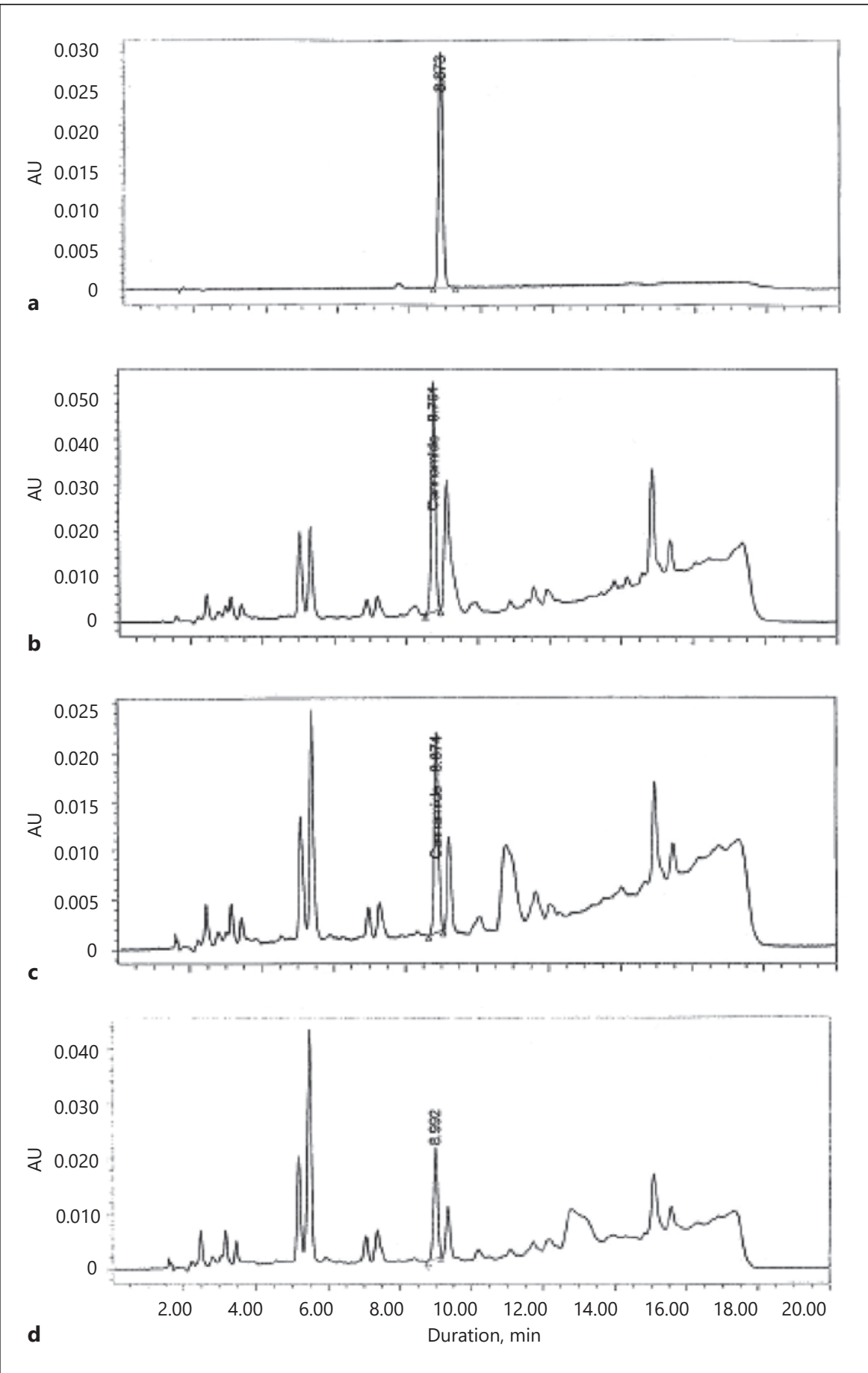

Fig. 4. Typical HPLC profiles of a $5 \mu \mathrm{g} / \mathrm{mL}$ standard p-coumaroyltyramine (10) (a), and $C$. sativa extracts $(\mathbf{b}-\mathbf{d})$ of a high CBD variety (b), intermediate variety (c), and high THC variety $(\mathbf{d})$.

\section{Disclosure Statement}

The authors have no financial or nonfinancial competing interest.
This research was partially supported by the National Institute on Drug Abuse (N01DA-15-7793) and by the Egyptian and Cultural Bureau, Washington, DC, USA.
Elhendawy/Wanas/Radwan/Azzaz/ Toson/ElSohly 


\section{References}

1 Radwan MM, Wanas AS, Chandra S, ElSohly MA. Phytocannabinoids in cannabis and methods of analysis. In: Chandra S, Lata, H, ElSohly MA, editors. Cannabis sativa L. Botany and Biotechnology. Cham: Springer; 2017. vol. 7, p. 161-182.

2 Zhou Y, Wang S, Lou H, Fan P. Chemical constituents of hemp (Cannabis sativa L.) seed with potential anti-neuroinflammatory activity. Phytochem Lett. 2018;23:57-61.

3 Ryz NR, Remillard DJ, Russo EB. Cannabis roots: a traditional therapy with future potential for treating inflammation and pain. Cannabis Cannabinoid Res. 2017 Aug;2(1): 210-6.

4 Grotenhermen F, Müller-Vahl K. The therapeutic potential of cannabis and cannabinoids. Dtsch Arztebl Int. 2012 Jul;109(29-30): 495-501.

5 Frank M, Rosenthal E. Cannabis and ancient history. In: Frank M, Wiliams O, Kallan L, editors. Marijuana grower's guide. Berkeley: And/Or Press; 1978. p. 3-10.

6 National Academies of Sciences Engineering Medicine: The health effects of cannabis and cannabinoids: The current state of evidence and recommendations for research. Washington: National Academies of Sciences Press; 2017.

7 Radwan MM, ElSohly MA, El-Alfy AT, Ahmed SA, Slade D, Husni AS, et al. Isolation and pharmacological evaluation of minor cannabinoids from high-potency Cannabis sativa. J Nat Prod. 2015 Jun;78(6):1271-6.
8 Radwan MM, Elsohly MA, Slade D, Ahmed SA, Khan IA, Ross SA. Biologically active cannabinoids from high-potency Cannabis sativa. J Nat Prod. 2009 May;72(5):906-11.

9 Radwan MM, Wanas AS, Fronczek FR, Jacob MR, Ross SA. Polybrominated diphenyl ethers from the marine organisms Lendenfeldia dendyi and Sinularia dura with anti-MRSa activity. Med Chem Res. 2015;24(9):3398404.

10 Samoylenko V, Jacob MR, Khan SI, Zhao J, Tekwani BL, Midiwo JO, Walker LA, Muhammad I: Antimicrobial, antiparasitic and cytotoxic spermine alkaloids from Albizia schimperiana. Nat Prod Commun. 2009 Jun; 4(6):791-6.

11 ICH I. Q2 (R1): Validation of analytical procedures: text and methodology: International Conference on Harmonization, Geneva, 2005.

12 Ageta H, Arai Y, Suzuki H, Kiyotani T, Kitabayashi M. NMR spectra of triterpenoids. III. Oleanenes and migrated oleanenes. Chem Pharm Bull (Tokyo). 1995;43(2):198-203.

13 Pierre LL, Moses MN. Isolation and characterisation of stigmasterol and $\beta$-sitosterol from Odontonema strictum (acanthaceae). J Innov Pharm Biol Sci. 2015;2:88-96.

14 Yaoita Y, Matsuki K, Iijima T, Nakano S, Kakuda R, Machida K, et al. New sterols and triterpenoids from four edible mushrooms. Chem Pharm Bull (Tokyo). 2001 May;49(5): 589-94.
15 Tariq M, Ali S, Ahmad F, Ahmad M, Zafar M, Khalid N, et al. Identification, FT-IR, NMR (1H and 13C) and GC/MS studies of fatty acid methyl esters in biodiesel from rocket seed oil. Fuel Process Technol. 2011;92(3):336-41.

16 Sacchi R, Addeo F, Paolillo L. 1H and 13C NMR of virgin olive oil. An overview. Magn Reson Chem. 1997;35(13):S133-45.

17 Mukonyi KW, Ndiege IO. 2-Hydroxy-4-methoxybenzaldehyde: aromatic taste modifying compound from Mondia whytei skeels. Bull Chem Soc Ethiop. 2001;15:137-42.

18 Peshin T, Kar H. Isolation and characterization of beta-sitosterol-3-O-beta-D-glucoside from the extract of the flowers of Viola odorata. Br J Pharm Res. 2017;16(4):1-8.

19 Chen C-Y, Yeh Y-T, Yang W-L: Amides from the stem of Capsicum annuum. Nat Prod Commun. $2011 \mathrm{Feb}$;6(2):227-9.

20 Shailajan S, Menon S, Singh A, Mhatre M, Sayed N, Joshi H, et al. Estimation of psoralen from herbal formulations containing Psoralea corylifolia using the RP-HPLC-DAD method and its application to a pharmacokinetic study. Int J Green Pharmacy. 2012;6(3):217223

21 Thyagaraj VD, Koshy R, Kachroo M, Mayachari AS, Sawant LP, Balasubramanium M. A validated RP-HPLC-UV/DAD method for simultaneous quantitative determination of rosmarinic acid and eugenol in Ocimum sanctum L. Pharm Methods. 2013;4(1):1-5.

22 Maji AK, Maity N, Banerji P, Banerjee D. Validated RP-HPLC-UV method for the determination of betulin in Asteracantha longifolia (L.) Nees. extract. Int J Phytomed. 2013;5: 131-5.
Chemical and Biological Studies of Cannabis sativa Roots
Med Cannabis Cannabinoids 2018;1:104-111 